\title{
Temperature dependent volatilisation behaviour of Cs from two commercial adsorbents used at Fukushima measured using novel experimental apparatus
}

Pletser, D.; Ohashi, T.; Yoshii, Y.; Lee, W. E.

\section{Progress in Nuclear Energy}

\author{
DOI: \\ 10.1016/j.pnucene.2018.08.003
}

Published: 01/11/2018

Peer reviewed version

Cyswllt i'r cyhoeddiad / Link to publication

Dyfyniad o'r fersiwn a gyhoeddwyd / Citation for published version (APA):

Pletser, D., Ohashi, T., Yoshii, Y., \& Lee, W. E. (2018). Temperature dependent volatilisation behaviour of Cs from two commercial adsorbents used at Fukushima measured using novel experimental apparatus. Progress in Nuclear Energy, 109, 214-222.

https://doi.org/10.1016/j.pnucene.2018.08.003

\footnotetext{
Hawliau Cyffredinol / General rights

Copyright and moral rights for the publications made accessible in the public portal are retained by the authors and/or other copyright owners and it is a condition of accessing publications that users recognise and abide by the legal requirements associated with these rights.

- Users may download and print one copy of any publication from the public portal for the purpose of private study or research.

- You may not further distribute the material or use it for any profit-making activity or commercial gain

- You may freely distribute the URL identifying the publication in the public portal ?
}

Take down policy

If you believe that this document breaches copyright please contact us providing details, and we will remove access to the work immediately and investigate your claim. 


\title{
Temperature dependent volatilisation behaviour of Cs from two commercial adsorbents used at Fukushima measured using novel experimental apparatus
}

\author{
D. Pletser ${ }^{1}$, T. Ohhashi $^{2}$, Y. Yoshii ${ }^{2}$ and W.E. Lee ${ }^{1}$
}

January 18, 2018

1 Centre for Nuclear Engineering, Imperial College London, Prince Consort Road, South Kensington, SW7 2AZ, London, United Kingdom

2 Center for Technology Innovation - Energy, Research \& Development Group, 7-2-1 Omika-cho, Hitachi-shi, Japan

Results from a custom-built experimental volatilisation apparatus are presented. The apparatus consists of a tubular furnace to volatilise and then entrain the volatilised species into a cooled segment to reprecipitate for collection. This design allows for meticulous collection of the volatilised species, which are then analysed with atomic absorption spectroscopy. This paper includes an evaluation of the apparatus and a comparative study of the temperature dependence of Cs volatilisation from two commercial adsorbents. The Cs volatilisation from A-51 JHP and IE-96 was examined from $600^{\circ} \mathrm{C}$ to $1000^{\circ} \mathrm{C}$. At $1000^{\circ} \mathrm{C}$ the relative volatilisation is found to be $1.67 \%$ for $\mathrm{A}-51$ JHP and $0.097 \%$ for IE-96. As the adsorbents require immobilisation contain volatile Cs species, the temperature dependence of this behaviour is important as it will affect Cs retention during the immobilisation process. The evaluation of the volatilisation apparatus showed it to be a reliable method to measure volatisation behaviour from adsorbents. 


\section{Introduction}

Many options exist for the disposal of nuclear waste, however most of them are high temperature processes[1]. These options are suitable for many types of waste, mainly those requiring a highly durable final waste form. One of the problems of high temperature immobilisation is that volatile species are often released and need to be dealt with appropriately[2-7]. Many melter configurations incorporate off-gas treatment to capture released volatiles [8]. Off-gas treatment usually uses standard particulate scrubbers, both wet and dry, and High Efficiency Particulate Air (HEPA) filters. Often specific steps are included to trap specific species[9], however this adds an extra waste stream to be treated, adding to the complexity of the immobilisation process[10].

Many nuclides can be volatile, mainly halogen species, but some can form these volatile halogens more readily than others. Both $\mathrm{Cs}$ and Sr are well-known for forming such species[5, 6, 11-13]. Other well known volatile species include, iodine, rhenium and technetium[14-18].

Due to the use of sea water as an emergency coolant during the early stages of the Fukushima response there is high $\mathrm{NaCl}$ content in the system[19]. Many of the fuel elements in the cores were exposed to sea water at temperatures above $1000^{\circ} \mathrm{C}$, which led to the formation of many chloride species in the coolant loop. The cooling water treated by the various Advanced Liquid Processing System (ALPS) is stored on-site[20]. This led to high concentrations of chlorides in the spent adsorbents [21]. Halogen retention during immobilisation has been studied by other authors [22] and both $\mathrm{CsCl}$ and $\mathrm{SrCl}$ species are well-known for being highly volatile and for forming volatile fractions[23] and work from Kamizono et al. [24-26] showed that volatilisation of Cs does occur from vitreous waste forms. Volatilisation of adsorbed nuclides from adsorbents used for radionuclide adsorption has been carried out by Ames and Knoll [27] and by Mimura and Kanno[28]. In the work of Mimura and Kanno Cs was volatilised from various commercially available adsorbents. A volatilisation experiment was performed using an experimental set-up that included various adsorbents that were heated to between $600^{\circ} \mathrm{C}$ and $1200^{\circ} \mathrm{C}$ and the volatilised Cs recovered from the apparatus and analysed[28].

Here we present the working of a custom experimental apparatus that can be used to determine temperature dependent volatilisation behaviour. This apparatus was then used to assess the Cs volatilisation behaviour from two modern, optimised, ion exchange adsorbents, IE-96 and A-51 JHP. 


\section{Materials and methods}

To assess the temperature dependence of volatilisation behaviour of Cs from commercial adsorbents an experimental apparatus was used. The temperature dependence of the Cs volatilisation behaviour served to set the temperature boundary for the processing conditions of waste form development[29]. Two different commercial adsorbents were tested using the volatilisation rig, A-51 JHP and IE-96. Both are commercially available from Union Showa (8-40, Konan 1-chome, Minato-ku, Tokyo 108-0075, Japan).

\subsection{Materials}

\subsubsection{A-51 JHP}

A-51 JHP is a zeolite and is a modified version of the A-51 beads available from the Honeywell UOP A-50 range. The A-50 range is a synthetic Linde Type A (LTA) zeolite, with the A-51 designating the bead form of the adsorbent[30]. LTA are a class of zeolites with known Cs adsorption capacity[31]. LTA has previously been used as an ion exchange adsorbent for many commercial applications. A-51 is optimised for $\mathrm{Sr}$ removal from wastewater, but is able to adsorb Cs and has been used in the Submerged Demineralizer System (SDS) at Three Mile Island[32, 33]. It has a reported selectivity series of $\mathrm{Sr}>\mathrm{Ca}>\mathrm{Na}, \mathrm{Mg}>\mathrm{K}>\mathrm{Rb}>\mathrm{Li}>\mathrm{Cs}[34]$.

\subsubsection{IE-96}

IE-96 is a zeolitic adsorbent with a large capacity for the sorption of $\operatorname{Cs}[31]$. It is a modified zeolite which was developed from naturally occurring chabazite, which has a large cation exchange capacity[35]. IE-96 was engineered and developed for the cleanup of the Three Mile Island NPP[36]. It is a Na-Chabazite[37] which is delivered in $1 \mathrm{~mm}$ granule form. It is used for the primary bulk removal of caesium at Fukushima, with a distribution coefficient $\left(\mathrm{K}_{\mathrm{d}}\right)$ of approximately 2000 relative to seawater. It is widely used for wastewater remediation as it has a high selectivity for Cs and has a reported selectivity series of $\mathrm{Cs}>\mathrm{K}>\mathrm{Na}>\mathrm{Li}, \mathrm{Ba}>\mathrm{Sr}>\mathrm{Ca}>\mathrm{Mg}[36,38]$.

\subsection{Experimental rig}

Volatilisation studies were performed at Hitachi Research Laboratories (7-1-1, Omikacho, Hitachi-shi, Ibaraki-ken 319-1292, Japan). Figure 1 shows the configuration of the rig, including gas lines, manifolds, regulators and wet traps. 


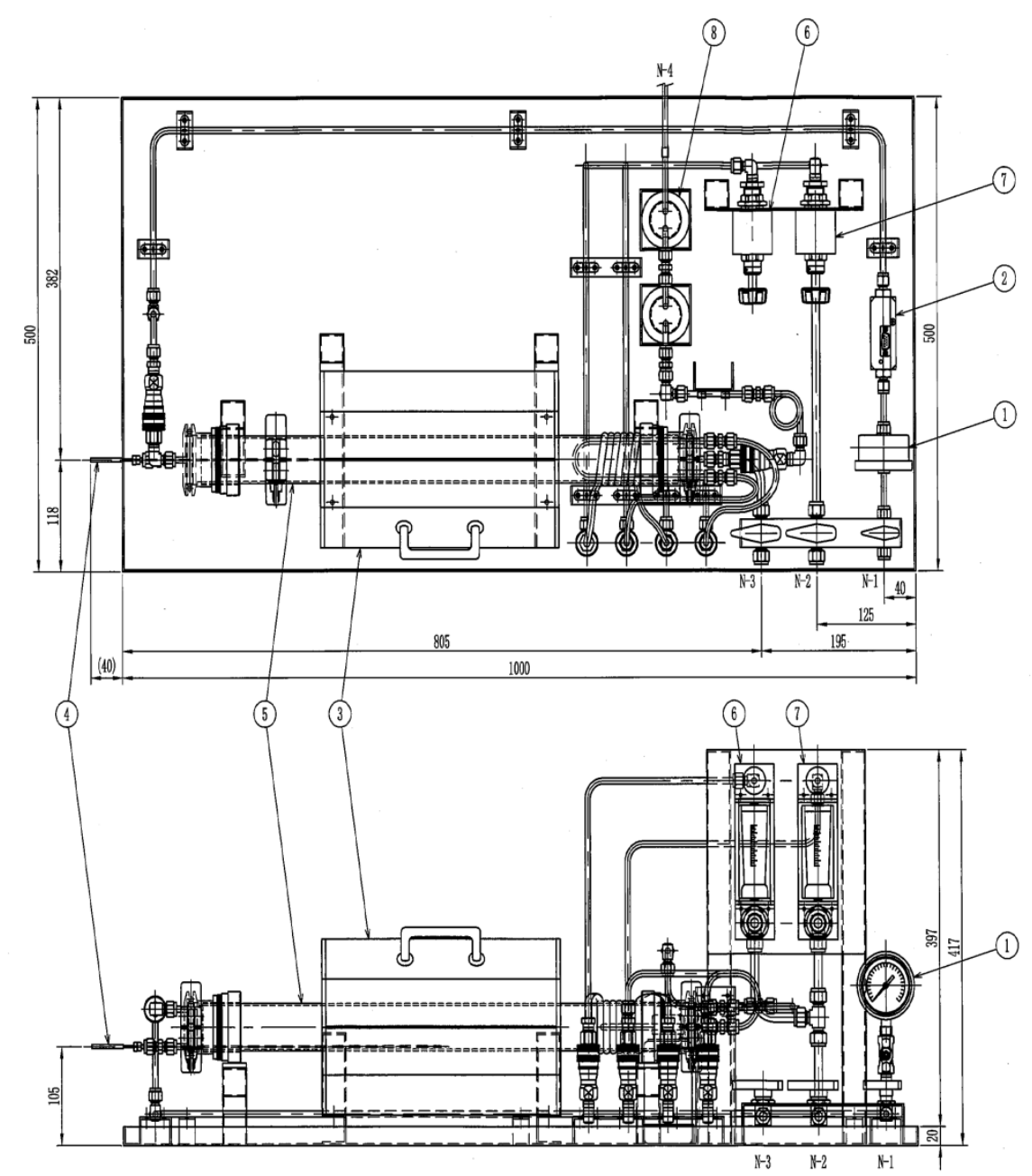

Figure 1: Technical diagram of experimental apparatus. Units in mm. Diagram key: 1. Gas flow pressure gauge; 2. MFC; 3. Heating mantle; 4. Thermocouple; 5. Fused quartz furnace tube; 6 . Cooling water flow meter $1 ; 7$. Cooling water flow meter $2 ; 8$. Wet traps.

The experimental set-up was a custom built tubular furnace. It consisted of a thermocoupled fused quartz tube furnace, with argon carrier gas, with a volumetric flow controlled by a Mass Flow Controller (MFC), a cooling system designed to condense volatilised Cs and two bubble traps designed to scrub the effluent carrier gas of Cs. The constructed set-up consisted of a fused quartz tube of $13 \mathrm{~mm}$ in diameter and $50 \mathrm{~cm}$ long. This tube was enclosed on either end with stainless steel flanges sealed with a pair of rubber O-rings. The flange on the entry side has an opening for inflow of carrier gas and a thermocouple which is protected by a fused quartz tip. The exit side of the furnace 
has a cooling loop, through which cooling water is pumped, around which fused quartz wool is folded to catch entrained Cs and an exhaust for the effluent carrier gas. The exhaust side of the tube is wrapped externally with flexible cooling tube through which cooling water is pumped and all exposed parts of the fused quartz tube are wrapped in insulating fused quartz wool wrap to avoid heat loss and unintended temperature gradients. This tube is placed in a heating mantle, which is a thermocoupled furnace. The sample is loaded on a fused quartz boat and placed in the middle of the tube. Argon carrier gas is flowed through the furnace to ensure that volatilised Cs is entrained to the cooling loop. The flow of argon gas is controlled by a MFC. The effluent gas is passed through two bubblers filled with $0.1 \mathrm{M} \mathrm{HNO}_{3}$, to ensure maximum Cs retention in the experimental set-up, as seen in Figure 2. 

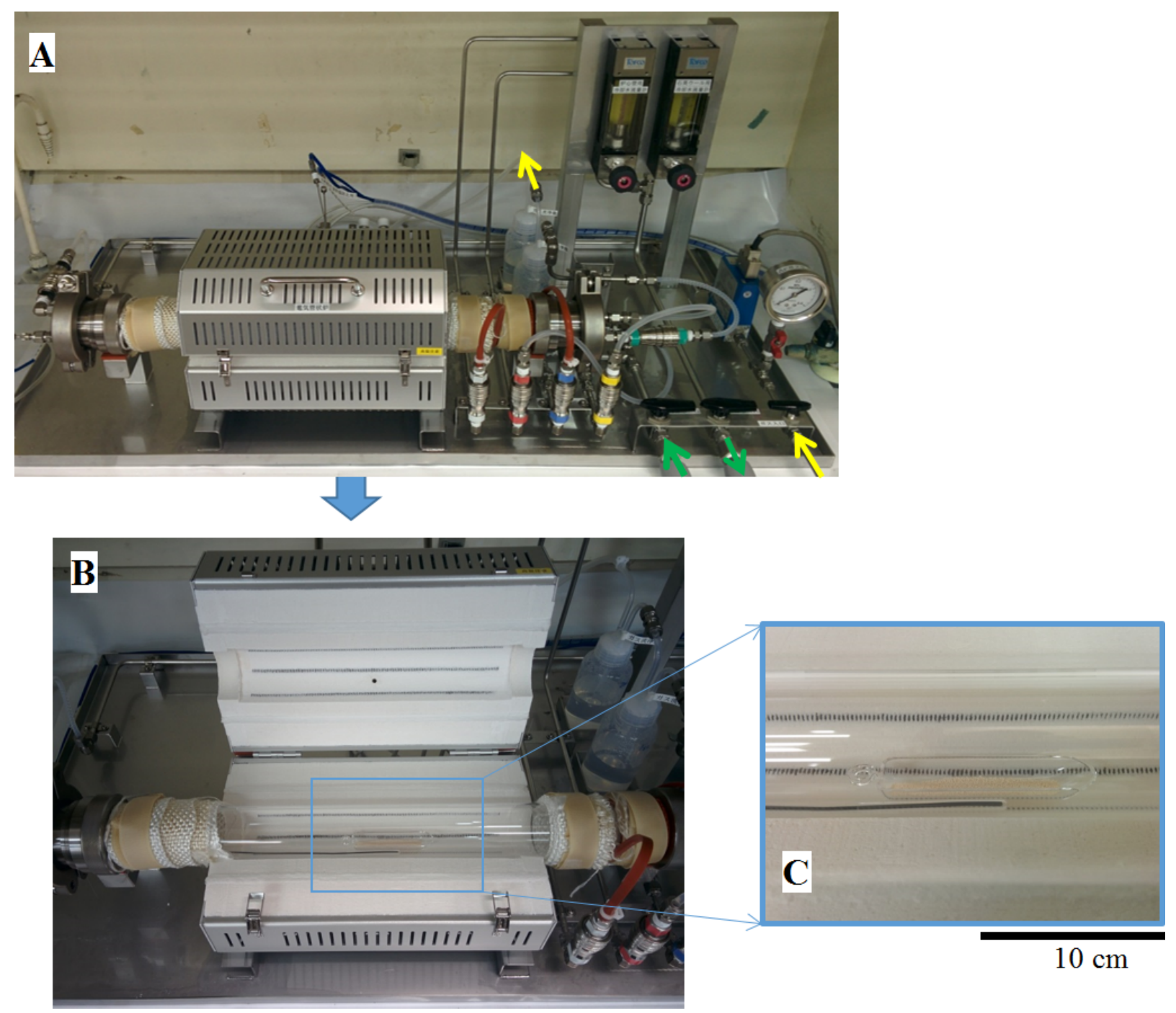

Figure 2: Furnace in operation (A) and with opened mantle (B). A) Green arrows show the in- and outflow of cooling water and yellow arrows show the in- and outflow of carrier gas. C) Inset image shows sample in fused quartz sample boat, with next to it thermocouple in protective fused quartz tip.

Figure 2 is a photograph of the set-up while it is in operation, illustrating clearly the fused quartz wool thermal insulating wraps covering the ends of the fused quartz tub. The second image in Figure 2 shows the heating mantle opened to show the inside of the tube, containing a fused quartz boat with sample and the thermocouple with a fused quartz tip. 


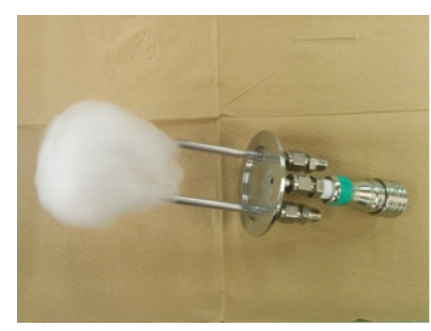

Fused quartz wool and cooling loop

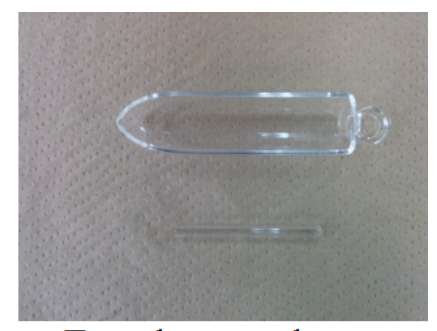

Fused quartz boat and protective tip

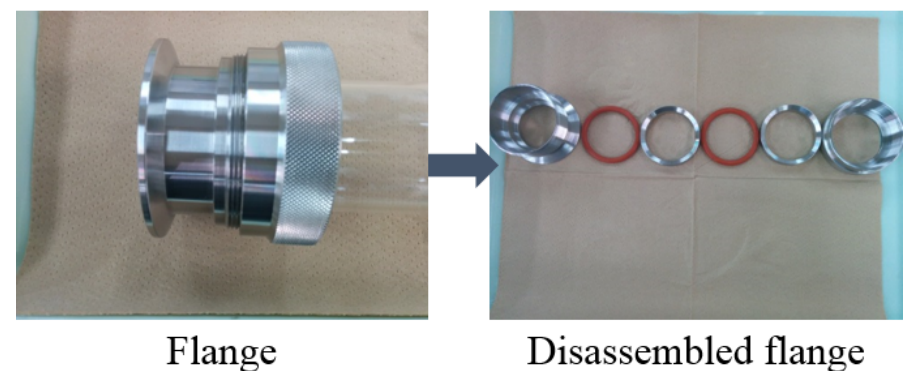

Figure 3: Various furnace components as labeled.

The fused quartz boat and protective thermocouple tip can be seen in more detail in Figure 3. The fused quartz tube can be completely removed from the wraps and the heating mantle while still keeping the stainless steel flanges on either end as seen in Figure 3. The flange consists of six components, which can be seen disassembled next to it. The six components, from left to right, are: the threaded bottom part of the flange, orange rubber O-ring, stainless steel spacer, rubber O-ring, stainless steel O-ring and threaded top of the flange. These parts assemble in that order onto the fused quartz tube and are screwed tight, with the two O-rings, separated by the stainless steel spacers, providing an impermeable seal. Once the flange is assembled and properly sealed, the end caps can be assembled, as in the top left hand of Figure 3 showing the exhaust side cap, complete with cooling loop and fused quartz wool collector. This end cap is secured with an O-ring and a screw-top clamp. The apparatus further consists of a cooling water and a MFC to ensure a consistent carrier gas flow. Three separate temperature controllers, one for the sample thermocouple, one for the furnace heating mantle and one emergency cut-off temperature controller ensure accurate measuring of the temperature. After furnace operations have been completed, a fan is used to ensure rapid cooling to room temperature, so that the shut down procedure can be performed as quickly as possible. 


\subsection{Experimental procedures}

\subsubsection{Furnace operation}

The furnace was meticulously stripped after every use, with each component washed in a $0.5 \mathrm{M} \mathrm{HNO}_{3}$ solution to ensure complete Cs recovery from the apparatus. The fused quartz tube and flanges were then assembled and mounted on the heating mantle. The cooling loop on the exhaust end cap was then covered in fused quartz wool and the end cap secured on the exhaust side of the fused quartz tube using a screw top clamp. The cooling tubes were hooked up to the cooling water pump, with coolant kept at $15.1^{\circ} \mathrm{C}$. The exhaust of the furnace was then connected to the bubblers and the outside of the furnace wrapped in insulating fused quartz wool wrap. The adsorbent was weighed in a fused quartz sample boat and inserted through an opening in the entrance side of the furnace and placed in the middle of the furnace. The thermocouple was secured through the end cap with its protective fused quartz cover over the tip of the thermocouple. The end cap was secured with a clamp and argon carrier gas flow is set to $10.2 \mathrm{~cm}^{3} /$ minute. Once everything was secured and both the cooling water and carrier gas flows were running the furnace was turned on and ramped up to the required temperature (with ramp rates between $25^{\circ} \mathrm{C} / \mathrm{min}$ and $60{ }^{\circ} \mathrm{C} / \mathrm{min}$ ). The sample temperature, as determined by the thermocouple, by the sample boat, was kept to within $\pm 1 \%$ of the set temperature by carefully controlling the output temperature of heating mantle. The sample was kept at the experimental temperature for $3 \mathrm{~h}$, after which it was allowed to cool under forced convection using a fan, with the mantle being opened up partially at $500^{\circ} \mathrm{C}$ and fully opened at $300^{\circ} \mathrm{C}$. Once the thermocouple temperature reached $50^{\circ} \mathrm{C}$, the carrier gas and cooling was shutdown.

\subsubsection{Adsorbent preparation}

As received adsorbent samples were treated by drying for $24 \mathrm{~h}$ in a desiccant-containing drying furnace at $80^{\circ} \mathrm{C}$. After this a $1000 \mathrm{ppm}$ Cs solution is prepared using ultra-pure water and $\mathrm{CsCl}$ (Sigma-Aldrich 99.99\% trace metal basis). This solution was analysed using atomic absorption spectroscopy (AAS) prior to sample loading to ensure an accurate wasteloading is achieved. The AAS used is a Hitachi High-Technologies ZA3700 (Hitachi High-Technologies, 24-14, Nishi-Shimbashi 1-chome, Minato-ku, Tokyo, 1058717, Japan). $1.00 \mathrm{~g}$ of the desiccated adsorbent was added to $100 \mathrm{ml}$ of the $1000 \mathrm{ppm}$ stock solution, and was contacted under static conditions for a minimum of $24 \mathrm{~h}$. Prior to sample use, the supernatant was carefully drained and retained for AAS analysis, to create a Cs mass balance and accurately determine the wt\% wasteloading of the ad- 
sorbent. The wet adsorbent was again dried at $80^{\circ} \mathrm{C}$ in the drying furnace containing desiccant. Once fully dry it was weighed out into the fused quartz sample boat and loaded into the furnace.

\section{Cs volatilisation results and discussion}

\subsection{Preparatory work}

\subsubsection{Cs recovery protocol}

The volatilisation experiments depend on volatilisation and deposition of Cs within the experimental apparatus. To gather accurate results on the Cs volatilisation behaviour from each of the adsorbents, the deposited Cs needs to be accurately recovered from the experimental apparatus, to enable its analysis by AAS. To this end a reproducible recovery protocol needed to be devised. The experimental apparatus consists of many different parts, most of which, may be contaminated with Cs after volatilisation. The first step in this process required documenting which parts of the experimental rig contained which parts of the Cs inventory. The initial experiments consisted of volatilising Cs and meticulously stripping and washing the experimental apparatus to recover individual Cs inventories and compare them to the full inventory. Some parts of the experimental set-up were not expected to be significantly contaminated, such as the outer ends of the quart tube flanges, as these were least likely to be exposed to any volatilised Cs. This is especially true of the flange at the entrance side of the tube, as the Cs was unlikely to diffuse against the flow of carrier gas. Other parts considered unlikely to have any deposited Cs were the inner O-rings of the flanges and the second bubbler, as most, if not all, Cs was expected to be retained in the first bubbler. The most probable places for Cs deposition were deemed to be tube, protective fused quartz tip of the thermocouple, fused quartz boat, fused quartz wool, internal cooling loop and the first wet trap.

To test this, $100 \mathrm{mg}$ of easily volatilised[12] $\mathrm{CsOH}$ was volatilised in the furnace, which was measured into a nickel steel alloy boat. In normal operation a fused quartz boat is used, however fused silica is attacked by $\mathrm{CsOH}[39]$, so to avoid etching the fused quartz boats and to ensure as much of the Cs as possible was available for recovery a nickel steel alloy boat was used for the experiments performed with $\mathrm{CsOH}$. The nickel steel boats were used for the $\mathrm{CsOH}$ volatilisation experiments during the protocol determination stage of work. Once work progressed to adsorbents fused quartz boats were used exclusively. Over the course of several experiments the inside of the tube was lightly etched by the volatilised $\mathrm{CsOH}$ (see Figure 4). This lead to patterns along the inside of 
the tube, corresponding to the path of the Cs as it is volatilised, entrained by the carrier gas and moves through the tube towards the exhaust.

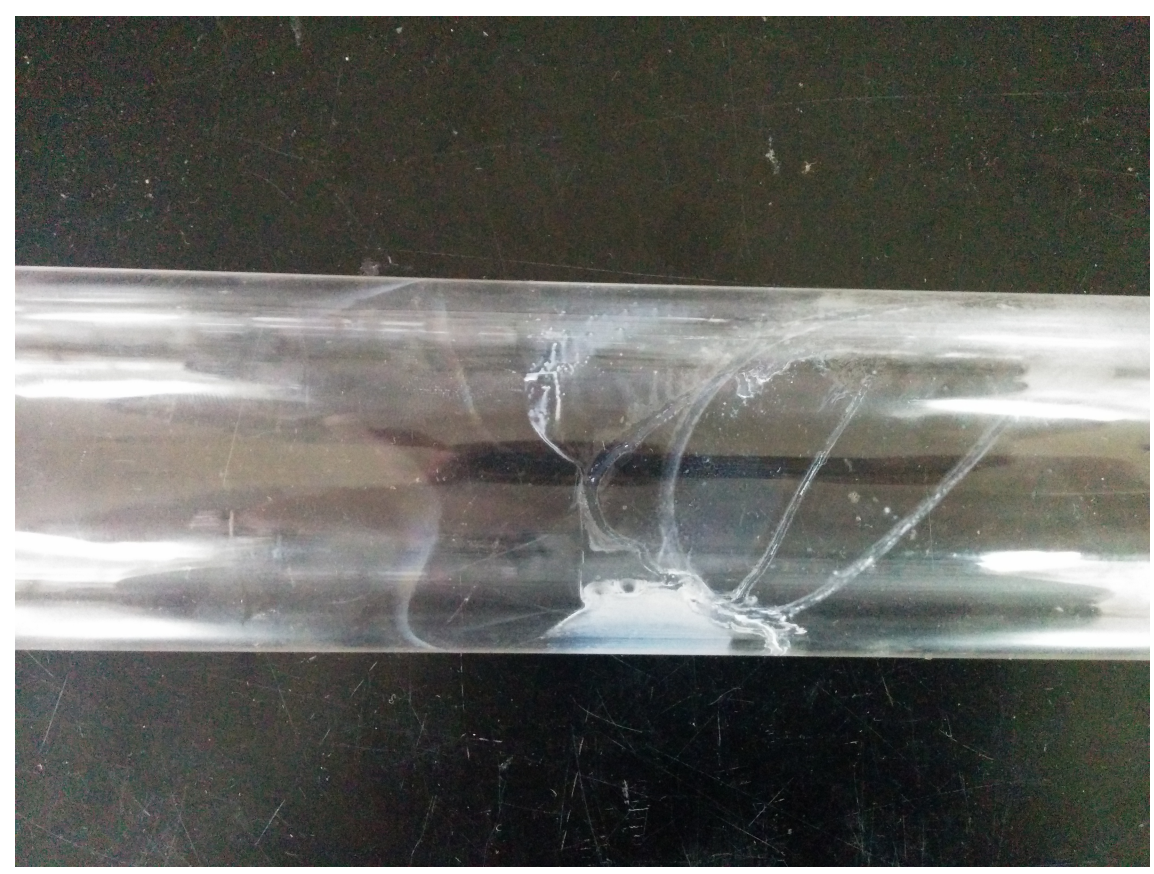

Figure 4: Fused quartz tube of Cs volatilisation rig, shows signs of etching after repeated $\mathrm{CsOH}$ volatilisation experiments

The $\mathrm{CsOH}$ volatilisation experiments were performed for $3 \mathrm{~h}$ at $800^{\circ} \mathrm{C}$, after which the apparatus was allowed to cool to room temperature. Once it had fully cooled, the fused quartz tube was removed from the heating mantle and carefully disassembled into its components. Each component was individually washed with ultra-pure water to recover all the Cs. All of these wash fractions were analysed using AAS to give an accurate Cs distribution within the experimental apparatus. The individual recovery from each of the parts of the set-up are given in Table 1, revealing that most of the recovered Cs was recovered from four components, the boat, the tube, the wool and the protective tip. These accounted for $99.88 \%$ of the Cs inventory.

Table 1: Ultra-pure water wash recovery of condensed $\mathrm{CsOH}$ volatilite

\begin{tabular}{|c|c|c|c|c|c|c|c|}
\hline Parts & ppb sample $(\mu \mathrm{g} / \mathrm{kg}) \pm \operatorname{RSD}(\%)$ & Dilution factor & ppb solution $(\mu \mathrm{g} / \mathrm{l})$ & M solution $(\mathrm{mol} / \mathrm{l})$ & Volume (1) & $\mathrm{mol} \mathrm{Cs}$ & Yield (\%) \\
\hline Boat & ch $24.4 \pm 2.6 \%$ & c1000 & $2.44 \times 10^{4}$ & $1.84 \times 10^{-4}$ & 0.25 & $4.59 \times 10^{-5} \pm 1.2 \times 10^{-6}$ & 40.25 \\
\hline Tube & $48.7 \pm 0.7 \%$ & 5000 & $2.43 \times 10^{5}$ & $1.83 \times 10^{-3}$ & 0.5 & $9.16 \times 10^{-4} \pm 6.6 \times 10^{-6}$ & 84.7 \\
\hline Tip & $28.7 \pm 2.7 \%$ & 5000 & $1.43 \times 10^{5}$ & $1.08 \times 10^{-5}$ & 0.1 & $1.08 \times 10^{-4} \pm 2.4 \times 10^{-6}$ & 9.97 \\
\hline Wool & $26.5 \pm 4.0 \%$ & 200 & $5.31 \times 10^{3}$ & $3.99 \times 10^{-5}$ & 0.25 & $9.98 \times 10^{-6} \pm 4.0 \times 10^{-7}$ & 0.923 \\
\hline Flange & $52.0 \pm 2.8 \%$ & 2 & $1.04 \times 10^{2}$ & $7.82 \times 10^{-7}$ & 0.1 & $7.82 \times 10^{-8} \pm 2.2 \times 10^{-9}$ & $7.24 \times 10^{-3}$ \\
\hline O-ring & $5.20 \pm 8.5 \%$ & 1 & 5.19 & $3.91 \times 10^{-8}$ & 0.1 & $3.91 \times 10^{-9} \pm 3.3 \times 10^{-10}$ & $3.61 \times 10^{-4}$ \\
\hline Cooling & $38.8 \pm 1.2 \%$ & 10 & $3.88 \times 10^{2}$ & $2.92 \times 10^{-6}$ & 0.1 & $2.92 \times 10^{-7} \pm 3.5 \times 10^{-9}$ & $2.70 \times 10^{-2}$ \\
\hline Wet trap 1 & $48.2 \pm 0.020 \%$ & 2 & $9.69 \times 10^{1}$ & $7.29 \times 10^{-7}$ & 0.15 & $1.09 \times 10^{-7} \pm 2.2 \times 10^{-11}$ & $1.01 \times 10^{-2}$ \\
\hline Wet trap 2 & $49.8 \pm 2.6 \%$ & 2 & $1.00 \times 10^{2}$ & $7.57 \times 10^{-7}$ & 0.15 & $1.13 \times 10^{-7} \pm 2.9 \times 10^{-9}$ & $1.04 \times 10^{-2}$ \\
\hline \multicolumn{6}{|c|}{ Total } & $1.08 \times 10^{-3}$ & 100 \\
\hline
\end{tabular}


These experiments were repeated, but after stripping the rig the constituent components were washed with a $0.5 \mathrm{M} \mathrm{HNO}_{3}$ solution and all fractions analysed using AAS to give a comparative Cs distribution. This decision was made to use a solution with some ionic strength to help Cs recovery. The levels of recovery with the nitric acid wash (Table 2) show similar trend, with the boat, the tube, the wool and the protective tip accounting for $99.97 \%$ of the Cs inventory.

Table 2: $0.5 \mathrm{M} \mathrm{HNO}_{3}$ wash recovery of $\mathrm{CsOH}$ volatilisation, $3 \mathrm{~h}$ at $800^{\circ} \mathrm{C}$

\begin{tabular}{|c|c|c|c|c|c|c|c|}
\hline Parts & ppb sample $(\mu \mathrm{g} / \mathrm{kg}) \pm \mathrm{RSD}(\%)$ & Dilution factor & ppb solution $(\mu \mathrm{g} / \mathrm{l})$ & M solution $(\mathrm{mol} / \mathrm{l})$ & Volume (1) & $\mathrm{mol} \mathrm{Cs}$ & Yield (\%) \\
\hline Boat & $\begin{array}{l}31.9 \pm 1.8 \% \\
\end{array}$ & (3000 & $9.61 \times 10^{4}$ & $7.23 \times 10^{-4}$ & 0.25 & 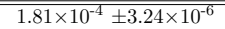 & 15.4 \\
\hline Tube & $25.5 \pm 0.3 \%$ & 10000 & $2.57 \times 10^{5}$ & $1.93 \times 10^{-3}$ & 0.5 & $9.65 \times 10^{-4} \pm 2.99 \times 10^{-6}$ & 82.2 \\
\hline Tip & $12.9 \pm 3.3 \%$ & 1000 & $1.30 \times 10^{4}$ & $9.78 \times 10^{-5}$ & 0.1 & $9.78 \times 10^{-6} \pm 3.2 \times 10^{-7}$ & 0.83 \\
\hline Wool & $32.8 \pm 2.4 \%$ & 300 & $9.89 \times 10^{3}$ & $7.44 \times 10^{-5}$ & 0.25 & $1.86 \times 10^{-5} \pm 4.4 \times 10^{-7}$ & 1.58 \\
\hline Flange & $52.0 \pm 4.1 \%$ & 2 & $1.05 \times 10^{2}$ & $7.87 \times 10^{-7}$ & 0.1 & $7.87 \times 10^{-8} \pm 3.2 \times 10^{-9}$ & $6.70 \times 10^{-3}$ \\
\hline O-ring & $55.6 \pm 2.2 \%$ & 1 & 55.9 & $4.21 \times 10^{-7}$ & 0.1 & $4.21 \times 10^{-8} \pm 9.2 \times 10^{-10}$ & $3.58 \times 10^{-3}$ \\
\hline Cooling & $0.72 \pm 54.2 \%$ & 1 & $7.236 \times 10^{-1}$ & $5.45 \times 10^{-9}$ & 0.1 & $5.45 \times 10^{-10} \pm 2.95 \times 10^{-10}$ & $4.63 \times 10^{-5}$ \\
\hline Wet trap 1 & $48.2 \pm 0.02 \%$ & 2 & 96.9 & $7.29 \times 10^{-7}$ & 0.15 & $1.09 \times 10^{-7} \pm 2.2 \times 10^{-11}$ & $9.31 \times 10^{-3}$ \\
\hline Wet trap 2 & $49.8 \pm 2.6 \%$ & 2 & $1.00 \times 10^{2}$ & $7.53 \times 10^{-7}$ & 0.15 & $1.13 \times 10^{-7} \pm 2.9 \times 10^{-9}$ & $9.61 \times 10^{-3}$ \\
\hline \multicolumn{6}{|c|}{ Total } & $1.17 \times 10^{-3}$ & 100 \\
\hline
\end{tabular}

These experiments were used to determine where the Cs was deposited and which washing medium recovered more Cs. The nitric acid wash was found to recover approximately $8.7 \%$ more $\mathrm{Cs}$ and therefore the use of the aqueous wash was discontinued. Experiments were continued with $0.5 \mathrm{M}$ nitric acid solution, to ensure increased Cs recovery. The Cs inventory of the nitric acid wash in Figure 2 reveals that the boat, fused quartz tube, protective tip and fused quartz wool account for the majority of the inventory.

Table 3: Cs inventory of boat, tube, tip and quartz wool in $0.5 \mathrm{M} \mathrm{HNO}_{3}, 3 \mathrm{~h}$ at $800^{\circ} \mathrm{C}$

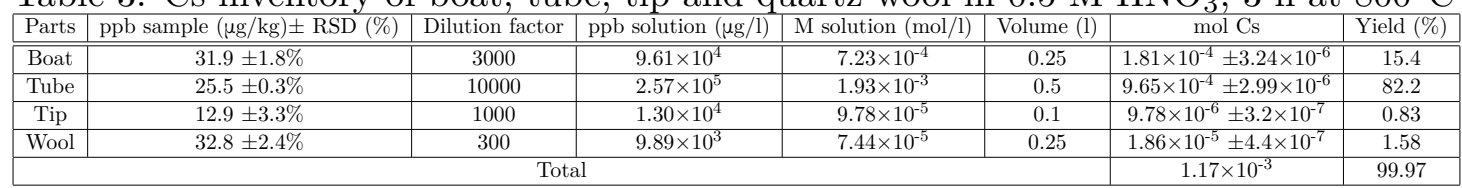

The inventory for those components (Table 3) accounts for $99.97 \%$ of the total Cs inventory. Normal operation of the furnace would always include AAS analysis of the wet traps, as high Cs concentrations in the wet traps would indicate a high Cs concentration in the effluent carrier gas exiting the furnace. Both wet traps contain $100 \mathrm{ml}$ of $0.1 \mathrm{M}$ $\mathrm{HNO}_{3}$ solution to ensure all effluent volatile $\mathrm{Cs}$ is caught. The effluent Cs may be due to improperly placed fused quartz wool or may point to other problems. If the second wet trap contains similarly high levels it might indicate that Cs may have escaped the set-up. This would require repeating the experiment to ensure a full Cs inventory. Once the two wet traps are taken into account, the yield of this experiment reaches $99.989 \%$ of the total inventory. This was deemed to be complete enough to continue with this recovery protocol. 


\subsubsection{Cs loading}

Once the furnace operation and recovery protocols were determined and optimised, the Cs loading required in the waste was determined. Two considerations needed to be addressed. One was that the amount of Cs present in the waste form needed to be sufficient to ensure that a Cs inventory was possible. The second consideration was that the model waste form needed to be as accurate as possible. This meant including a Cs loading on par with what the real adsorbents might reasonably be expected to contain. Of these, the former consideration was prioritised and ensuring enough Cs to be able to create an accurate Cs inventory was deemed more important from the outset. Before volatilisation experiments could be started an appropriate Cs loading needed to be determined. To this end A51-JHP was prepared with Cs loadings of $10 \mathrm{ppm}, 100$ ppm and 1000 ppm. A Cs balance, an example of which is shown in Tables 4, 5 and 6, and was created for every treated adsorbent sample that was volatilised and this allows for accurate tracking of Cs throughout the process from stock solution preparation, to adsorbent loading to volatilisation and finally recovery. Table 4 shows the starting stock solutions that were used for the adsorbent loading.

Table 4: Starting Cs concentration for 3 different solutions

\begin{tabular}{|c|c|c|c|c|c|c|}
\hline Parts & ppb sample $(\mu \mathrm{g} / \mathrm{kg}) \pm$ RSD $(\%)$ & Dilution factor & ppb solution $(\mu \mathrm{g} / \mathrm{l})$ & M solution $(\mathrm{mol} / \mathrm{l})$ & Volume $(\mathrm{l})$ & $\mathrm{mol}$ Cs \\
\hline \hline $10 \mathrm{ppm}$ start & $31.0 \pm 1.1 \%$ & 400 & $1.24 \times 10^{4}$ & $9.324 \times 10^{-5}$ & 0.1 & $9.32 \times 10^{-6} \pm 1.1 \times 10^{-7}$ \\
\hline $10 \mathrm{ppm}$ start & $31.0 \pm 1.1 \%$ & 400 & $1.24 \times 10^{4}$ & $9.324 \times 10^{-5}$ & 0.1 & $9.32 \times 10^{-6} \pm 1.1 \times 10^{-7}$ \\
\hline $100 \mathrm{ppm}$ start & $48.2 \pm 2.0 \%$ & 2000 & $9.63 \times 10^{4}$ & $7.25 \times 10^{-4}$ & 0.1 & $7.248 \times 10^{-5} \pm 1.5 \times 10^{-6}$ \\
\hline $100 \mathrm{ppm}$ start & $48.2 \pm 2.0 \%$ & 2000 & $9.63 \times 10^{4}$ & $7.25 \times 10^{-4}$ & 0.1 & $7.248 \times 10^{-5} \pm 1.5 \times 10^{-6}$ \\
\hline $1000 \mathrm{ppm}$ start & $47.7 \pm 1.2 \%$ & 20000 & $9.54 \times 10^{5}$ & $7.18 \times 10^{-3}$ & 0.1 & $7.18 \times 10^{-4} \pm 8.4 \times 10^{-6}$ \\
\hline $1000 \mathrm{ppm}$ start & $47.7 \pm 1.2 \%$ & 20000 & $9.54 \times 10^{5}$ & $7.18 \times 10^{-3}$ & 0.1 & $7.18 \times 10^{-4} \pm 8.4 \times 10^{-6}$ \\
\hline
\end{tabular}

Cs adsorption was performed under static conditions. A $\mathrm{CsCl}$ solution was prepared and analysed using AAS. $100 \mathrm{ml}$ of the analysed $\mathrm{CsCl}$ solution was then contacted with $1.00 \mathrm{~g}$ of the A-51 JHP for $24 \mathrm{~h}$. The adsorbent was then removed from solution and dried at $80^{\circ} \mathrm{C}$ for $3 \mathrm{~h}$. The solution was analysed using AAS to accurately determine how much Cs was adsorbed by the adsorbent. Table 5 shows concentrations of Cs in the solutions after loading for $24 \mathrm{~h}$.

Table 5: Final concentrations for 3 different solutions after $24 \mathrm{~h}$ of loading

\begin{tabular}{|c|c|c|c|c|c|c|}
\hline Sample & ppb sample $(\mu \mathrm{g} / \mathrm{kg}) \pm$ RSD $(\%)$ & Dilution factor & ppb solution $(\mu \mathrm{g} / \mathrm{l})$ & M solution $(\mathrm{mol} / \mathrm{l})$ & Volume $(\mathrm{l})$ & mol Cs \\
\hline \hline $10 \mathrm{ppm} 5$ & $29.2 \pm 2.4 \%$ & 200 & $5.84 \times 10^{3}$ & $4.39 \times 10^{-5}$ & 0.1 & $4.39 \times 10^{-6} \pm 1.1 \times 10^{-7}$ \\
\hline $10 \mathrm{ppm} 6$ & $34.0 \pm 5.6 \%$ & 200 & $6.80 \times 10^{3}$ & $5.11 \times 10^{-5}$ & 0.1 & $5.11 \times 10^{-6} \pm 2.9 \times 10^{-7}$ \\
\hline $100 \mathrm{ppm} 1$ & $24.9 \pm 11.9 \%$ & 2000 & $4.98 \times 10^{4}$ & $3.75 \times 10^{-4}$ & 0.1 & $3.75 \times 10^{-5} \pm 4.5 \times 10^{-6}$ \\
\hline $100 \mathrm{ppm} 2$ & $34.3 \pm 1.8 \%$ & 2000 & $6.86 \times 10^{4}$ & $5.16 \times 10^{-4}$ & 0.1 & $5.16 \times 10^{-5} \pm 9.3 \times 10^{-7}$ \\
\hline $1000 \mathrm{ppm} 9$ & $11.5 \pm 9.7 \%$ & 20000 & $2.30 \times 10^{5}$ & $1.73 \times 10^{-3}$ & 0.1 & $1.73 \times 10^{-4} \pm 1.7 \times 10^{-5}$ \\
\hline $1000 \mathrm{ppm} 10$ & $11.7 \pm 1.3 \%$ & 20000 & $2.33 \times 10^{5}$ & $1.76 \times 10^{-3}$ & 0.1 & $1.76 \times 10^{-4} \pm 2.3 \times 10^{-6}$ \\
\hline
\end{tabular}

The difference between Tables 4 and 5 were used to determine the amount of Cs adsorbed to the adsorbent. This mass balance and loading can be seen in Table 6 . 
Table 6: Mass balances and final wasteloadings for three different solution concentrations

\begin{tabular}{|c|c|c|c|c|c|}
\hline Zeolite mass (g) & Sample & Adsorbed (mol) & Adsorbed (\%) & Adsorbed (g) & Cs loading (wt\%) \\
\hline \hline 1.0007 & 5 & $4.93 \times 10^{-6} \pm 1.5 \times 10^{-7}$ & 52.9 & $6.55 \times 10^{-4}$ & 0.0655 \\
\hline 1.008 & 6 & $4.21 \times 10^{-6} \pm 3.1 \times 10^{-7}$ & 45.2 & $5.60 \times 10^{-4}$ & 0.0555 \\
\hline 1.009 & 1 & $3.50 \times 10^{-5} \pm 4.7 \times 10^{-6}$ & 48.3 & $4.65 \times 10^{-3}$ & 0.461 \\
\hline 1.0079 & 2 & $2.09 \times 10^{-5} \pm 1.7 \times 10^{-6}$ & 28.8 & $2.77 \times 10^{-3}$ & 0.275 \\
\hline 1.007 & 9 & $5.45 \times 10^{-4} \pm 1.9 \times 10^{-5}$ & 75.9 & $7.24 \times 10^{-2}$ & 7.19 \\
\hline 0.9999 & 10 & $5.42 \times 10^{-4} \pm 8.7 \times 10^{-6}$ & 75.5 & $7.21 \times 10^{-2}$ & 7.21 \\
\hline
\end{tabular}

The treated and dried adsorbents were then volatilised for $3 \mathrm{~h}$ at $800^{\circ} \mathrm{C}$. Cs was recovered using the optimised nitric acid wash protocol detailed previously (Section 3.1.1) and the recovered solutions analysed using AAS. The results from the $10 \mathrm{ppm}$ and the $100 \mathrm{ppm}$ loaded adsorbents fell below AAS detection limits, however the $1000 \mathrm{ppm}$ loaded sample allowed for a full Cs inventory which can be seen in Table 7 .

Table 7: Cs inventory $1000 \mathrm{ppm}$ loaded A-51 JHP, $3 \mathrm{~h}$ at $800^{\circ} \mathrm{C}$. The "wash" fraction contains all wash fractions from the boat, tube, protective tip and quartz wool.

\begin{tabular}{|c|c|c|c|c|c|c|}
\hline Parts & ppb sample $(\mu \mathrm{g} / \mathrm{kg}) \pm$ RSD $(\%)$ & Dilution factor & ppb solution $(\mu \mathrm{g} / \mathrm{l})$ & M solution $(\mathrm{mol} / \mathrm{l})$ & Volume $(\mathrm{l})$ & mol Cs \\
\hline \hline Wash & $19.6 \pm 7.5 \%$ & 1 & 19.7 & $1.48 \times 10^{-7}$ & 0.503 & $7.45 \times 10^{-8} \pm 5.6 \times 10^{-9}$ \\
\hline Wet trap 1 & $1.25 \pm 40.8 \%$ & 1 & 1.26 & $9.45 \times 10^{-9}$ & 0.15075 & $1.43 \times 10^{-9} \pm 5.8 \times 10^{-10}$ \\
\hline Wet trap 2 & $0.65 \pm 6.2 \%$ & 1 & 0.653 & $4.92 \times 10^{-9}$ & 0.15075 & $7.41 \times 10^{-10} \pm 4.6 \times 10^{-11}$ \\
\hline \multicolumn{7}{|c|}{ Total } \\
\hline
\end{tabular}

Using $100 \mathrm{ml}$ of $1000 \mathrm{ppm}$ solution to load $1.00 \mathrm{~g}$ of adsorbent leads to an effective wasteloading of approximately $7-8 \mathrm{wt} \%$ in all cases, in all the different adsorbents. For all results presented in this paper the wasteloading was confirmed to be $7-8 \mathrm{wt} \%$.

\subsubsection{Relative volatilisation}

The data from the AAS analysis of all samples were examined for their repeatability. The AAS is calibrated before every set of samples is run and needs to be re-calibrated every 10 samples. Calibration is performed with four standards, a $0 \mathrm{ppb}, 10 \mathrm{ppb}, 25$ $\mathrm{ppb}$ and $50 \mathrm{ppb}$. A linear calibration curve is drawn between the absolute absorption and the concentration of the standards with required $r^{2}$ value of the calibration curve falling at 0.9999 before analysis can proceed. As it is calibrated to maximum $50 \mathrm{ppb}$, all samples submitted to it for analysis must fall between 0 and $50 \mathrm{ppb}$ to ensure that it is covered by the calibration curve. This often requires diluting the solutions to ensure that they fall in this range. In the case of unknown concentrations, estimates must be made for each sample beforehand. Occasionally this means that samples need to be run multiple times with different dilution factors to ensure accurate and reliable data. 
The volatilisation data is presented as the relative volatilisation which is defined as:

$$
\text { Relative volatilisation }(\%)=\frac{\text { Total recovered Cs }(\mathrm{mol})}{\text { Total Cs in sample }(\mathrm{mol})} \times 100 \%
$$

The relative volatilisation for every sample was calculated using this equation. However, both the total recovered $\mathrm{Cs}$ in mol and the total Cs in the sample consists of multiple AAS measurements. The total recovered Cs is calculated by the addition of three different AAS values. The wash of the tube and parts, wet trap 1 and wet trap 2 . The total measure of Cs in the sample is the Cs balance over the adsorbent, with the difference in Cs concentration in the stock solution and the solution after adsorption. This is the total amount of Cs present in the system during the volatilisation.

\subsection{A-51 JHP}

The volatilisation experiments were performed over 5 temperatures ranging from 600 to $1000^{\circ} \mathrm{C}$. The experiments were performed at $100^{\circ} \mathrm{C}$ intervals. The samples were heated to their final temperature where they were held for $3 \mathrm{~h}$, after which they were allowed to cool to $500^{\circ} \mathrm{C}$, then the heating mantle was opened before the system was cooled under forced convection until it reached room temperature. The sample was then recovered and the rig disassembled and washed using the recovery protocol specified in Section 3.1.1. The first low temperature experiment was performed at $600^{\circ} \mathrm{C}$. Samples of $1.00 \mathrm{~g}$ of 1000 ppm loaded A-51 JHP placed in the fused quartz boat before being inserted into the fused quartz tube and the furnace closed and started up. After $3 \mathrm{~h}$ at $600^{\circ} \mathrm{C}$ the furnace was left to cool until at $500^{\circ} \mathrm{C}$ the furnace mantle was opened and the furnace cooled by forced convection using a fan. The sample was then carefully removed and the tube and boat subjected to the optimised washing protocol.

Table 8: Relative volatilisation behaviour of Cs from A-51 JHP. ND indicates below detection limit.

\begin{tabular}{|c|c|c|c|c|c|}
\hline Temperature $\left({ }^{\circ} \mathrm{C}\right)$ & 600 & 700 & 800 & 900 & 1000 \\
\hline \hline A-51 JHP relative volatilisation (\%) & ND & ND & $0.0145 \pm 0.00059$ & $1.07 \pm 0.054$ & $1.67 \pm 0.073$ \\
\hline
\end{tabular}

The collected wash fractions and wet trap contents were analysed using AAS and the full Cs inventory was obtained for all samples (See Table 8). Cs deposition in the tube was found to be below the detection limit and no Cs was found in the wet traps. This was followed by another set of experiments at $700^{\circ} \mathrm{C}$, which showed Cs volatilisation to be below detection limits of the AAS. However the experiments at $800^{\circ} \mathrm{C}$ started showing volatilisation, on the order of $0.01 \%$, which was followed by a dramatic increase 
in volatilisation at $900^{\circ} \mathrm{C}$ on the order of $1 \%$, followed by an increase at $1000^{\circ} \mathrm{C}$ of the same order. This evolution of the relative volatilisation of Cs from A-51 JHP as a function of temperature can be seen in Figure 5.

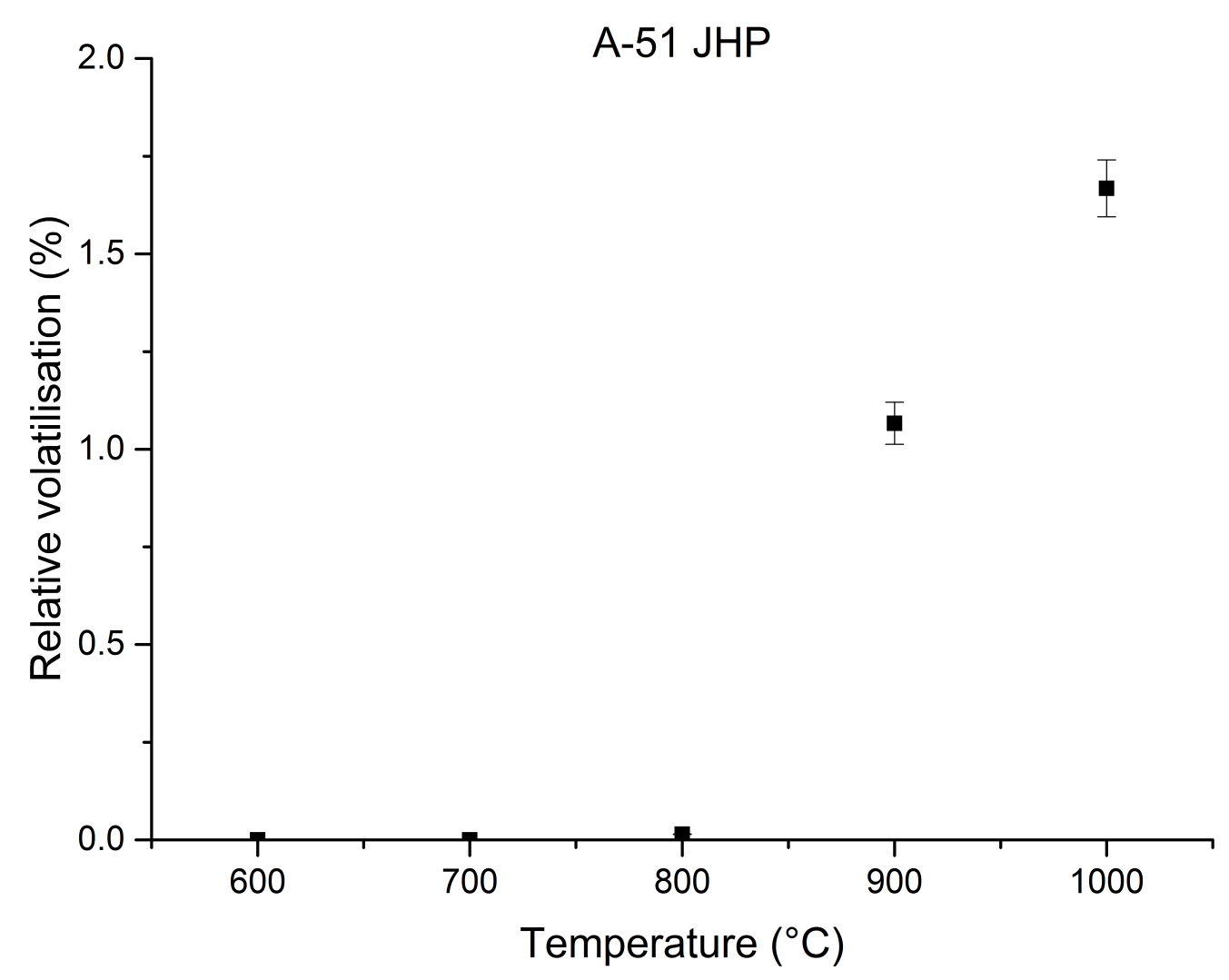

Figure 5: Relative volatilisation of Cs from A-51 JHP as a function of temperature

\subsection{IE-96}

The volatilisation of Cs from IE-96 was performed from $600^{\circ} \mathrm{C}$ to $1000^{\circ} \mathrm{C}$. Samples of $1.00 \mathrm{~g}$ of $1000 \mathrm{ppm}$ Cs loaded IE-96 were loaded into the fused quartz boat which was loaded into the furnace. The furnace was held isothermally for $3 \mathrm{~h}$ at the experimental temperature, after which the Cs was recovered with the optimised protocol shown in Section 3.1.1. 
Table 9: Relative volatilisation behaviour of Cs from IE-96. ND indicates below detection limit

\begin{tabular}{|c|c|c|c|c|c|}
\hline Temperature $\left({ }^{\circ} \mathrm{C}\right)$ & 600 & 700 & 800 & 900 & 1000 \\
\hline \hline IE-96 relative volatilisation (\%) & ND & ND & ND & $0.0318 \pm 0.0012$ & $0.0966 \pm 0.0042$ \\
\hline
\end{tabular}

Collected wash fractions and wet traps analysed for Cs using AAS (Table 9) fell below AAS detection limits, after heating at $600^{\circ} \mathrm{C}, 700^{\circ} \mathrm{C}$ and $800^{\circ} \mathrm{C}$. This was expected, as preliminary experiments using less sophisticated techniques showed no volatilisation until $800^{\circ} \mathrm{C}$. At $900^{\circ} \mathrm{C}$ volatilisation could be observed, with relative values on the order $0.01 \%$ and a three-fold increase at $1000^{\circ} \mathrm{C}$, with a relative volatilisation of around $0.1 \%$. The relative volatilisation behaviour as a function of temperature is shown in Figure 6 . 


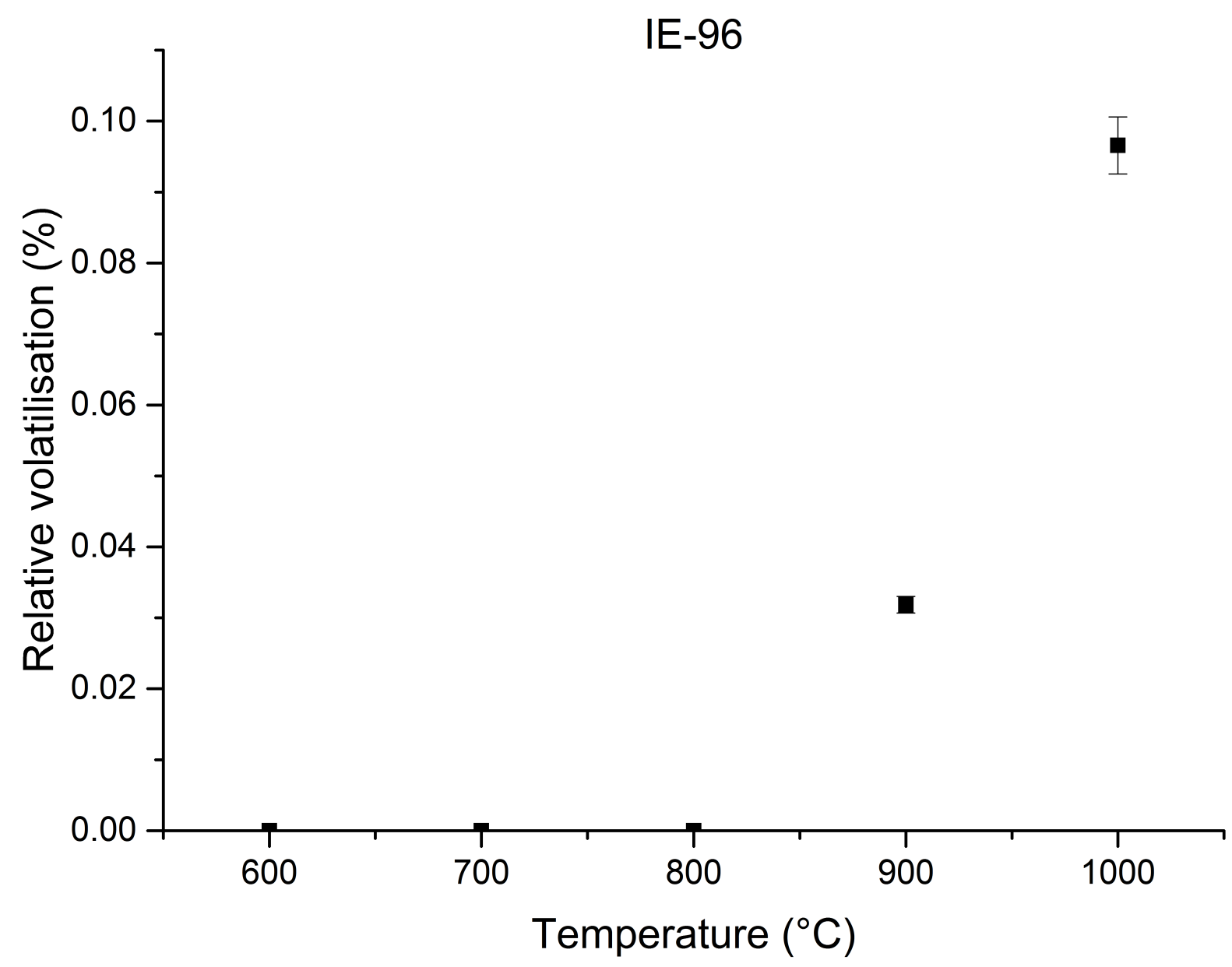

Figure 6: Relative volatilisation of Cs from IE-96 as a function of temperature

\subsection{Combined behaviour}

There is an obvious difference in behaviour between IE-96 and A-51 (See Figure 7). IE-96 shows good volatilisation resistance with its relative volatilization behaviour remaining below $0.1 \%$ in all successful experiments. However, A-51 JHP has a relative volatilization of an order of magnitude higher, approximately $1.67 \%$ at $1000^{\circ} \mathrm{C}$. A possible reason for these behaviours may be differences in Cs selectivities and thermal stability at higher temperatures. While IE-96 is a chabazite with a high Cs selectivity, A-51 JHP is synthetic zeolite designed for Sr capture, not Cs. The high Cs selectivity of IE-96 would 
suggest improved Cs retention, when compared to the A-51 JHP.

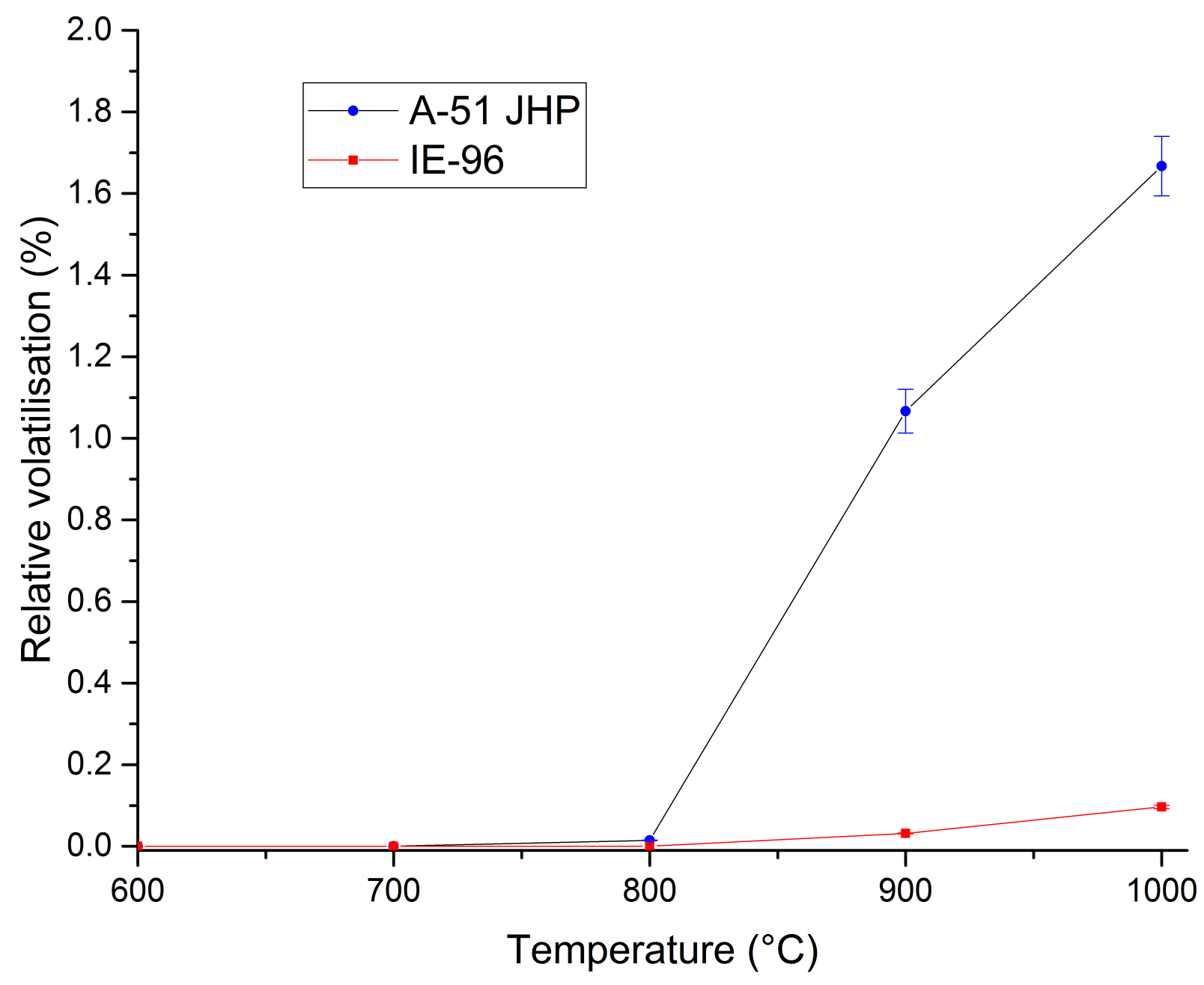

Figure 7: Combined volatilisation behaviour of A-51 JHP, IE-96

Radionuclide volatilisation is a concern for many high temperature processes. Previous work has often focused on long-term volatilisation from nuclear waste forms and the volatilisation from high temperature vitrification processes $[2-4,7,9-11,14,15,23-$ 26]. Volatilisation behaviour from adsorbents is a topic on which comparatively little research has been done. The method presented here, using a custom-built volatilisation apparatus, shows great potential in this field. The workings of the apparatus are fully explored and found to be able to accurately measure Cs during volatilisation experiments 
up to $1000^{\circ} \mathrm{C}$. The use of this apparatus will allow for further systematic exploration of volatilisation behaviour.

Mimura and Kanno[28] systematically investigated into the volatilisation behaviour from a mix of commercial adsorbents and natural analogues. All adsorbents were tested up to $1200^{\circ} \mathrm{C}$. The results of Mimura and Kanno are comparable to those from this work as it shows the behaviour of Cs volatilisation to increase as temperature increases. They also noted that the selectivity of the adsorbent influenced the retention of the Cs, with higher selectivity correlating to more Cs retention[28]. The data from IE-96 is similar to the reported data from Mimura and Kanno concerning the behaviour of the adsorbents which have high reported Cs selectivities [28, 31]. If we only compare the Cs selective adsorbents from our study, IE-96, to the adsorbents from the Mimura and Kanno study, we see similar behaviour, as IE-96 behaves in the same fashion as the adsorbents tested by Mimura and Kanno, which is expected. The A-51 JHP is less selective to Cs than the IE-96, and the Cs volatilisation behaviour from the A-51 JHP increases accordingly.

While temperature dependent volatilisation behaviour from these materials is important for processing considerations, not much recent literature on the subject is available. The non-exhaustive list from Mimura and Kanno is an important one and shows the behaviour for a number of adsorbents, but no recent, publicly available, work details the Cs volatilisation behaviour from adsorbents. The adsorbents detailed here are advanced engineered adsorbents, specifically tailored to their purpose, with modifications to increase selectivity and capacity. This will likely influence the Cs retention at higher temperature, making this work important as it serves to show the Cs retention of these newer, more advanced, materials at higher temperature.

\section{Conclusion}

A custom-built rig consisting of a tubular furnace made of fused quartz, in which samples of two adsorbents, loaded with realistic Cs wt\%, were heated to $1000^{\circ} \mathrm{C}$ was evaluated. The volatilised Cs was then recovered and analysed using AAS to determine the relative volatilisation from two commercial adsorbents. The adsorbents examined, A-51 JHP and IE-96, are both currently used in the Fukushima Dai-ichi remediation efforts. The volatilisation was found to be strongly temperature dependent, with no volatilisation occurring at $600^{\circ} \mathrm{C}$ in two of the three adsorbents and minimal relative volatilisation, on the order of $0.01 \%$, in the third. At higher temperatures the Cs volatilisation behaviours started to differ, depending on the Cs selectivity of the material and the adsorbent material properties. A-51 JHP has a lower Cs selectivity than both IE-96 and IE-911, 
leading to a stronger volatilisation behaviour at higher temperatures. IE-96 has been optimised for Cs selectivity, leading to much reduced Cs volatilisation behaviour. IE-96 was found to perform the best, as even at $1000^{\circ} \mathrm{C}$ it showed $\mathrm{Cs}$ volatilisation on the order of $0.1 \%$.

\section{Acknowledgments}

We would like to thank Hitachi-GE Nuclear Energy Ltd. for funding this research. Furthermore the authors would like to thank Sellafield Ltd. for their support of this project.

\section{References}

[1] W.E. Lee, M.I. Ojovan, M.C. Stennett, and N.C. Hyatt. Immobilisation of radioactive waste in glasses, glass composite materials and ceramics. Advances in Applied Ceramics, 105:3-12, 2006.

[2] G. W. Wilds. Vaporization of semi-volatile components from Savannah River Plant waste glass. Technical Report DP-1504, Savannah River Lab, 1978.

[3] B. P. Spalding and G. K. Jacobs. Evaluation of an in-situ vitrification field demonstration of a simulated radioactive liquid waste disposal trench. Technical Report ORNL/TM10992, Oak Ridge National Laboratory, 1989.

[4] B.P. Spalding, G.K. Jacobs, N.W. Dunbar, M.T. Naney, J.S. Tixier, and T.D. Powell. Tracer-level radioactive pilot-scale test of in-situ vitrification for the stabilization of contaminated soil states at ORNL. Technical Report ORNL/TM-12201, Oak Ridge National Laboratory, 1992.

[5] B.G. Parkinson, D. Holland, M.E. Smith, A.P. Howes, and C.R. Scales. The effect of $\mathrm{Cs}_{2} \mathrm{O}$ additions on HLW wasteform glasses. Journal of Non-Crystalline Solids, $351(30): 2425-2432,2005$.

[6] B.G. Parkinson. Influence of Composition on Structure and Caesium Volatilisation from Glasses for HLW Confinement. PhD thesis, University of Warwick, UK, 2007.

[7] I. Ghiloufi and C. Girold. Optical Emission Spectroscopy measurements and simulation of radioelement volatility during radioactive waste treatment by plasma. Plasma Chemistry and Plasma Processing, 31(1):109-125, 2011. 
[8] J.G. Darab and P.A. Smith. Chemistry of technetium and rhenium species during low-level radioactive waste vitrification. Chemistry of Materials, 8(5):1004-1021, 1996.

[9] J.R. Zamecnik and A.S. Choi. Impact of eliminating mercury removal pretreatment on the performance of a high-level radioactive waste melter offgas system. Environmental Engineering Science, 27(7):593-611, 2010.

[10] I.H. Yoon, W.K. Choi, S.C. Lee, B.Y. Min, H.C. Yang, and K.W. Lee. Volatility and leachability of heavy metals and radionuclides in thermally treated HEPA filter media generated from nuclear facilities. Journal of Hazardous Materials, 219:240246,2012 .

[11] C.W. Sill. Volatility of cesium and strontium from a synthetic basalt. Nuclear and Chemical Waste Management, 8(2):97 - 105, 1988.

[12] F.Z. Roki, C. Chatillon, M.N. Ohnet, and D. Jacquemain. Thermodynamic study of the $\mathrm{CsOH}(\mathrm{s}, \mathrm{l})$ vaporization by high temperature mass spectrometry. The Journal of Chemical Thermodynamics, 40(3):401 - 416, 2008.

[13] S.R. Mallampati, Y. Mitoma, T. Okuda, C. Simion, and B.K. Lee. Dynamic immobilization of simulated radionuclide ${ }^{133} \mathrm{Cs}$ in soil by thermal treatment/vitrification with nanometallic $\mathrm{Ca} / \mathrm{CaO}$ composites. Journal of Environmental Radioactivity, 139:118-124, 2015.

[14] G.J. Evans. Measurement and modeling of iodine volatility above irradiated CsI solutions. Nuclear Technology, 116(3):293-305, 1996.

[15] M.H. Langowski, J.G. Darab, and P.A. Smith. Volatility literature of chlorine, iodine, cesium, strontium, technetium and rhenium; technetium and rhenium volatility testing. Technical Report PNNL-11052, 1996.

[16] K. Xu, D.A. Pierce, P. Hrma, M.J. Schweiger, and A.A. Kruger. Rhenium volatilization in waste glasses. Journal of Nuclear Materials, 464:382-388, 2015.

[17] J.G. Darab and P.A. Smith. Chemistry of technetium and rhenium species during low-level radioactive waste vitrification. Chemistry of Materials, 8(5):1004-1021, 1996.

[18] M.S. Lee, W. Um, G. Wang, A.A. Kruger, W.W. Lukens, R. Rousseau, and V.A. Glezakou. Impeding ${ }^{99} \mathrm{Tc}$ (IV) mobility in novel waste forms. Nature Communications, 7, 2016. 
[19] Y. Kani, M. Kamosida, D. Watanabe, T. Asano, and S. Tamata. Removal of radionuclides from waste water at Fukushima Daiichi nuclear power plant: Desalination and adsorption methods. In Proceedings of Waste Management, number 13126, pages 24-28. Waste Management, Waste Management Symposia, 2013.

[20] D. Pletser. Novel Wasteforms for Caesium-containing Spent Adsorbents from Fukushima Daiichi: A Study of Volatilisation and Low-temperature Glass Processing. PhD thesis, Imperial College London, United Kingdom, 2017.

[21] M. Baba. Fukushima accident: What happened? Radiation Measurements, 55:17 - 21, 2013. 7th International Workshop on Ionizing Radiation Monitoring.

[22] P.R. Hrma. Retention of halogens in waste glass. Technical Report PNNL-19361, Pacific Northwest National Laboratory, Richland US, 2010.

[23] B.P. Spalding. Volatilization of cesium-137 from soil with chloride amendments during heating and vitrification. Environmental Science \& Technology, 28(6):11161123, 1994.

[24] H. Kamizono, S. Kikkawa, S. Tashiro, and H. Nakamura. Volatilization of cesium from nuclear waste glass in a canister. Nuclear Technology, 72(1):84-88, 1986.

[25] H. Kamizono, S. Kikkawa, S. Tashiro, H. Nakamura, and H. Kanazawa. Air contamination by cesium in a canister containing nuclear waste glass. Journal of Nuclear Materials, 149(1):113-116, 61987.

[26] H. Kamizono, S. Kikkawa, Y. Togashi, and S. Tashiro. Volatilization of ${ }^{137}$ Cs and ${ }^{106} \mathrm{Ru}$ from borosilicate glass containing actual high-level waste. Journal of the American Ceramic Society, 72(8):1438-1441, 1989.

[27] L.L. Ames Jr and K.C. Knoll. Loading and elution characteristics of some natural and synthetic zeolites. Technical Report HW-74609, General Electric Co. Hanford Atomic Products Operation, Richland, Wash., 1962.

[28] H. Mimura and T. Kanno. Processing of radioactive waste solution with zeolites, (IV). Journal of the Atomic Energy Society of Japan / Atomic Energy Society of Japan, 20(4):282-287, 1978.

[29] D. Pletser, R. K. Chinnam, M. Kamoshida, and W.E. Lee. Immobilisation process for contaminated zeolitic ion exchangers from fukushima. MRS Advances, 1(62):4089-4094, 2017. 
[30] Y. Ikarashi, R. S. Masud, T. Nakai, H. Mimura, E. Ishizaki, M. Matsukura, and Y. Hosoi. Selective adsorption properties and stable solidification of Cs by insoluble ferrocyanide loaded zeolites. Journal of Energy and Power Engineering, 8(3):61, 2014.

[31] M.W. Munthali, E. Johan, H. Aono, and N. Matsue. $\mathrm{Cs}^{+}$and $\mathrm{Sr}^{2+}$ adsorption selectivity of zeolites in relation to radioactive decontamination. Journal of Asian Ceramic Societies, 3(3):245-250, 2015.

[32] E.D. Collins, D.O. Campbell, L.J. King, and J.B. Knauer. Evaluation of zeolite mixtures for decontaminating High-Activity-Level water at the Three Mile Island Unit 2 Nuclear Power Station. In American Institute of Chemical Engineers Symposium, volume 78 of $A$, page 9,1982 .

[33] R. Nagaishi, K. Morita, I. Yamagishi, R. Hino, and T. Ogawa. Revaluation of hydrogen generation by water radiolysis in SDS vessels at TMI-2 accident. In Proceedings of Nuclear Plant Chemistry, volume 2, pages 1675-1684. Atomic Energy Society of Japan, 2014.

[34] H. Mimura, S. Susa, Y. Ito, Y. Saito, and M. Matsukura. Adsorption properties of Sr (II) on zeolite type adsorbents and their irradiation stabilities. In 2014 22nd International Conference on Nuclear Engineering, volume 4, page V004T08A003. American Society of Mechanical Engineers, 2014.

[35] V. J. Inglezakis. The concept of capacity in zeolite ion-exchange systems. Journal of Colloid and Interface Science, 281(1):68-79, 2005.

[36] Honeywell UOP. UOP IONSIV Ion Exchangers: Efficient treatment of liquid nuclear wastes. Technical Report UOP5649a, 2012.

[37] H. Mimura, T. Kobayashi, and K. Akiba. Chromatographic separation of strontium and cesium in mixed zeolite column. Journal of Nuclear Science and Technology, 32(1):60-67, 1995.

[38] Honeywell UOP. UOP IONSIV Selective Media: Water Decontamination at Japan's Fukushima Daiichi Nuclear Power Plant. Technical Report UOP5845-1, 2013.

[39] M.J. Matthewson, V.V. Rondinella, B. Lin, and S.W. Keyes. Effect of alkali hydroxides on the strength and fatigue of fused silica optical fiber. Journal of the American Ceramic Society, 74(10):2592-2598, 1991. 